\title{
CARACTERÍSTICAS DA ATIVIDADE DA PEROXIDASE DE ABACAXIS (Ananas comosus (L.) Merrill) DA CULTIVAR IAC GOMO-DE-MEL E DO CLONE IAC-1
}

\author{
Carlos Alexandre Koguishi de BRITO ; Hélia Harumi SATO ; \\ Ademar SPIRONELLO; ; Walter José SIQUEIRA
}

\begin{abstract}
RESUMO
No presente trabalho foram estudadas as características bioquímicas das peroxidases de novos abacaxis, cultivar IAC Gomo-demel e clone IAC- 1 . As peroxidases dos sucos destes abacaxis apresentaram atividade ótima entre $45^{\circ} \mathrm{C}$ e $50^{\circ} \mathrm{C}$ e entre $50^{\circ} \mathrm{C}$ e $55^{\circ} \mathrm{C}$, respectivamente. Estas peroxidases apresentaram atividade ótima em pH 4,5 e mostraram-se estáveis na faixa de pH 4,0 a 9,0, retendo, após 24 horas de incubação a $50^{\circ} \mathrm{C}$, mais de $80 \%$ da atividade inicial. Foi observada regeneração parcial da atividade da peroxidase, após tratamento a $75^{\circ} \mathrm{C}$ por 10 minutos. As peroxidases dos sucos dos abacaxis estudados foram inativadas, após tratamento a $90^{\circ} \mathrm{C}$ por 2 minutos.
\end{abstract}

Palavras-chave: Ananas comosus; abacaxi; peroxidase; regeneração; inativação.

\section{SUMMARY}

BIOCHEMICAL CHARACTERISTICS PEROXIDASE FROM PINEAPPLE (Ananas Comosus (L.) Merrill): CULTIVAR IAC GOMO-DEMEL AND CLONE IAC-1. In the present work, the biochemical characteristics of peroxidase enzymes from new pineapples, cultivar IAC Gomo-de-mel and clone IAC-1, were studied. The peroxidases obtained from the juice of this pineapples presented optimum activities from $45^{\circ} \mathrm{C}$ to $50^{\circ} \mathrm{C}$ and $50^{\circ} \mathrm{C}$ to $55^{\circ} \mathrm{C}$, respectively. These peroxidases showed maximum activity at pH 4.5 and showed stability at $\mathrm{pH} 4.0$ to 9.0 , retaining after 24 hours of incubation at $50^{\circ} \mathrm{C}$ more than $80 \%$ of initial activity. Partial regeneration of peroxidase activity was observed after treatment at $75^{\circ} \mathrm{C}$ for 10 minutes. The peroxidases from pineapple juices studied were inactivated after treatment at $90^{\circ} \mathrm{C}$ for 2 minutes.

Keywords: Ananas comosus; pineapple; peroxidase; enzyme inactivation.

\section{1 - INTRODUÇÃO}

A peroxidase (E.C.1.11.1.7., doador $\mathrm{H}_{2} \mathrm{O}_{2}$ oxidoredutase) é uma enzima associada a reações de deterioração oxidativa em frutas e vegetais in natura e produtos processados [6]. Na reação enzimática o peróxido de hidrogênio ou outro peróxido orgânico, como o peróxido de metila ou o etil hidrogênio, é reduzido, enquanto que um doador de elétrons $\left(\mathrm{AH}_{2}\right)$ é oxidado. O doador de elétrons pode ser ascorbato, fenóis, aminas ou outros compostos orgânicos [17, 21]. Em muitos casos o produto da oxidação é colorido e serve como base para a determinação colorimétrica da atividade da peroxidase.

A peroxidase pode causar mudanças indesejáveis no aroma, gosto, cor, textura e também a perda de nutrientes $[1,5,7,22]$. A peroxidase pode participar da destruição de vitamina $\mathrm{C}$, catalizar o branqueamento dos carotenóides na ausência de ácidos graxos insaturados e a

Recebido para publicação em 23/04/2003. Aceito para publicação em 17/03/2005(001102).

Departamento de Ciência de Alimentos/Faculdade de Engenharia de Alimentos/Universidade Estadual de Campinas. End.: Cidade Universitária "Zeferino Vaz". Caixa Postal 6121; Barão Geraldo. CEP: 13083-970 Campinas/SP. E-mail: brito@bol.com.br e heliah@fea.unicamp.br

Centro de Genética, Biologia Molecular e Fitoquimica do Instituto Agronômico de Campinas. End.: Av. Barão de Itapura, 1481, CEP: 13020-902-Campinas/SP.

A quem a correspondência deve ser enviada. descoloração de antocianinas. Catalisa a reação de degradação de ácidos graxos insaturados, produzindo voláteis que alteram o sabor [16] .

Desde 1991, o Instituto Agronômico de Campinas vem desenvolvendo um programa de melhoramento genético do abacaxi, visando a resistência à fusariose e características agrícolas e organolépticas mais desejáveis [20].

O IAC selecionou alguns clones de abacaxi, além da cultivar IAC Gomo-de-mel, recentemente indicado para cultivo, o qual reúne vários fatores desejáveis: elevado teor de sólidos solúveis totais, acidez de baixa a moderada, consistência tenra, suculência e coloração amareloouro atraente. O abacaxi "IAC Gomo-de-mel" também apresenta como característica, gomos que podem ser destacados manualmente [20].

Por ser de interesse conhecer algumas características da enzima peroxidase do abacaxi 'IAC Gomo-de-mel' e do clone IAC- 1 foram determinadas a faixa de $\mathrm{pH}$ e a temperatura ótima de atividade, o $\mathrm{pH}$ e a temperatura de estabilidade da enzima e a regeneração, após tratamento térmico e sua inativação térmica.

\section{2 - MATERIAL E MÉTODOS}

\section{1 - Preparo do extrato bruto}

As amostras do abacaxi 'IAC Gomo-de-mel' e do clone IAC-1, em estádio de maturação de $1 / 4$ a 1 / 2 de casca amarela, foram coletadas na Estação Experimental de Agronomia de Pindorama-SP, pertencente ao Instituto 
Agronômico de Campinas. As amostras de polpa foram homogeneizadas em liquidificador e o suco obtido por centrifugação a 11.000 .g por 10 minutos, a $5^{\circ} \mathrm{C}$, foi utilizado como fonte de peroxidase.

\section{2 - Determinação da atividade de peroxidase}

A atividade de peroxidase dos extratos de abacaxi baseou-se no método de KHAN \& ROBINSON [9]. A mistura de $1,5 \mathrm{~mL}$ de guaiacol a $1 \%$ em tampão de fosfato a $0,05 \mathrm{M}$ e pH 6,0 com $1,2 \mathrm{~mL}$ deste tampão foi incubada, a $25^{\circ} \mathrm{C}$, em cubeta do espectrofotômetro Beckman DU 70. Em seguida adicionou-se $0,1 \mathrm{~mL}$ do extrato enzimático diluído e $0,4 \mathrm{~mL}$ de solução de $\mathrm{H}_{2} \mathrm{O}_{2}\left(0,33 \mathrm{~mL}\right.$ de $\mathrm{H}_{2} \mathrm{O}_{2}$ a $30 \%$ em $100 \mathrm{~mL}$ de tampão fosfato a $0,05 \mathrm{M}$ e pH 6,0). O aumento da absorbância a $470 \mathrm{~nm}$ foi monitorado durante 5 minutos de reação a $25^{\circ} \mathrm{C}$, contra um branco, no qual a solução de $\mathrm{H}_{2} \mathrm{O}$ foi substituída pelo tampão.

As análises foram feitas em três repetições, utilizando-se amostras do extrato enzimático diluído. Uma unidade de atividade de peroxidase (U) foi definida como a quantidade de enzima que causa aumento na absorbância de 0,001 por minuto a $470 \mathrm{~nm}$, tendo o guaiacol como doador de $\mathrm{H}$.

\section{3 - Determinação das características bioquí- micas das peroxidases}

A determinação das características das peroxidases dos abacaxis estudados quanto à temperatura e $\mathrm{pH}$ ótimos, temperatura e $\mathrm{pH}$ para estabilidade, regeneração após tratamento térmico e inativação térmica foram realizadas em três repetições, utilizando-se amostras do extrato enzimático diluídas.

\subsection{1 - Efeito da temperatura}

A determinação da temperatura ótima para a atividade das peroxidases foi realizada entre $10^{\circ} \mathrm{C}$ a $70^{\circ} \mathrm{C}$, com intervalos de $10^{\circ} \mathrm{C}$, que foram reduzidos para $5^{\circ} \mathrm{C}$ na região da atividade ótima. A temperatura em que foi verificada a atividade ótima foi utilizada nas determinações subseqüentes.

\subsection{2 - Efeito do $\mathrm{pH}$}

A influência do $\mathrm{pH}$ na atividade da peroxidase foi determinada usando-se tampões citrato-fosfato com $\mathrm{pH}$ variando de 2,6 a 7,0 a 0,2M, em intervalos de 0,5 unidades de $\mathrm{pH}$. A determinação da faixa ótima de $\mathrm{pH}$ foi feita a $50^{\circ} \mathrm{C}$, substituindo-se o tampão fosfato a $0,05 \mathrm{M} \mathrm{e} \mathrm{pH} 6,0$, da mistura de reação, pelas diferentes soluções tampão.

\subsection{3 - Efeito da temperatura na estabilidade}

A estabilidade térmica das peroxidases foi testada através de dois tratamentos térmicos. Inicialmente as amostras de extrato enzimático foram incubadas a $30^{\circ} \mathrm{C}$, $40^{\circ} \mathrm{C}, 50^{\circ} \mathrm{C}, 60^{\circ} \mathrm{C}, 70^{\circ} \mathrm{C}, 80^{\circ} \mathrm{C}, 90^{\circ} \mathrm{C}$ e temperatura de ebulição $\left(97^{\circ} \mathrm{C}\right)$, por 30 minutos. Em seguida, as amostras eram resfriadas em banho de gelo e a atividade residual determinada, nas condições ótimas de pH e tempe- ratura para a atividade da peroxidase do abacaxi. Na segunda etapa e após se ter verificado que somente em temperaturas maiores que $70^{\circ} \mathrm{C}$ ocorreu diminuição da atividade, testou-se as temperaturas de $85^{\circ} \mathrm{C}, 90^{\circ} \mathrm{C}$ e $95^{\circ} \mathrm{C}$ por $30,60,120$ e 180 segundos.

\subsection{4 - Regeneração da atividade da peroxidase após o tratamento térmico}

O teste foi baseado no método descrito por MC LELLAN \& ROBINSON [13]. As amostras do extrato enzimático foram aquecidas a $75^{\circ} \mathrm{C}$ por 10 minutos e a $90^{\circ} \mathrm{C}$ por 2 minutos, sendo em seguida armazenadas a $5^{\circ} \mathrm{C}$ e $25^{\circ} \mathrm{C}$. A atividade residual da enzima foi determinada após 3 horas e 24 horas de incubação nas condições ótimas de atividade da peroxidase, $\mathrm{pH} 4,5$ e $50^{\circ} \mathrm{C}$.

\subsection{5 - Efeito do pH na estabilidade}

O efeito do $\mathrm{pH}$ na estabilidade das peroxidases foi testado na faixa de 3,0 a 9,0, em tampão citrato-fosfato a $0,05 \mathrm{M}$ e borato/ácido bórico a $0,05 \mathrm{M}$, a intervalos de 1 unidade de $\mathrm{pH}$. Alíquotas de $0,5 \mathrm{~mL}$ do extrato enzimático e $0,5 \mathrm{~mL}$ das soluções tampão foram incubadas a $5^{\circ} \mathrm{C}$ por 24 horas, a $25^{\circ} \mathrm{C}$ por 3 horas e a $50^{\circ} \mathrm{C}$ por 3 horas e 24 horas. Após essa incubação, foi adicionado o tampão citrato-fosfato a $0,05 \mathrm{M} \mathrm{e} \mathrm{pH} \mathrm{4,5,} \mathrm{para} \mathrm{ajustar} \mathrm{todas} \mathrm{as} \mathrm{amos-}$ tras para um mesmo $\mathrm{pH}$ e em seguida determinou-se a atividade residual, nas condições ótimas de atividade da peroxidase, $\mathrm{pH} 4,5$ e $50^{\circ} \mathrm{C}$.

\section{RESULTADOS E DISCUSSÃO}

As peroxidases dos abacaxis "IAC Gomo-de-mel" e do clone IAC-1 apresentaram temperatura ótima para a atividade, na faixa de $45^{\circ} \mathrm{C}$ a $50^{\circ} \mathrm{C}$ e de $50^{\circ} \mathrm{C}$ a $55^{\circ} \mathrm{C}$, respectivamente (Figura 1). Estes resultados são similares aos obtidos para as peroxidases de carambola [8], kiwi [19] e melão [10], que apresentaram temperatura ótima para atividade na faixa de $50^{\circ} \mathrm{C}$ a $55^{\circ} \mathrm{C}$. As peroxidases de maçã [15], morango [3] e pêssego [12] mostraram atividade ótima a $25^{\circ} \mathrm{C}, 30^{\circ} \mathrm{C}$ e $40^{\circ} \mathrm{C}$, respectivamente.

As peroxidases dos abacaxis 'IAC Gomo-de-mel' e IAC- 1 apresentaram atividade ótima em $\mathrm{pH} 4,5$, a $50^{\circ} \mathrm{C}$, e baixa atividade em pH 2,6 e superiores a 7,0 (Figura 2). As peroxidases desses abacaxis atuam melhor em $\mathrm{pH}$ ácido, concordando com os resultados obtidos por BEAUDREAU \& YASUNOBU [2] que relataram que a peroxidase de abacaxi apresentava $\mathrm{pH}$ ótimo de atividade em pH 4,2, e por FERREIRA \& CABRAL [4] que verificou que a peroxidase de abacaxi cv. Pérola, apresentava atividade ótima em pH 5,0.

As peroxidases dos abacaxis apresentaram atividade em pH mais ácido quando comparada com as peroxidases de outras frutas. As peroxidases de pêssego [12] e manga [9] mostraram atividade ótima em $\mathrm{pH}$ 5,0, as de carambola [8] e kiwi [19] apresentaram em torno de $\mathrm{pH}$ 5,5 , enquanto que as do morango [3] e açaí [18] mostraram-na em $\mathrm{pH}$ 6,0. A peroxidase de melão [10] apresentou atividade ótima em $\mathrm{pH}$ na faixa de $\mathrm{pH} 6,0$ a 7,0, a 


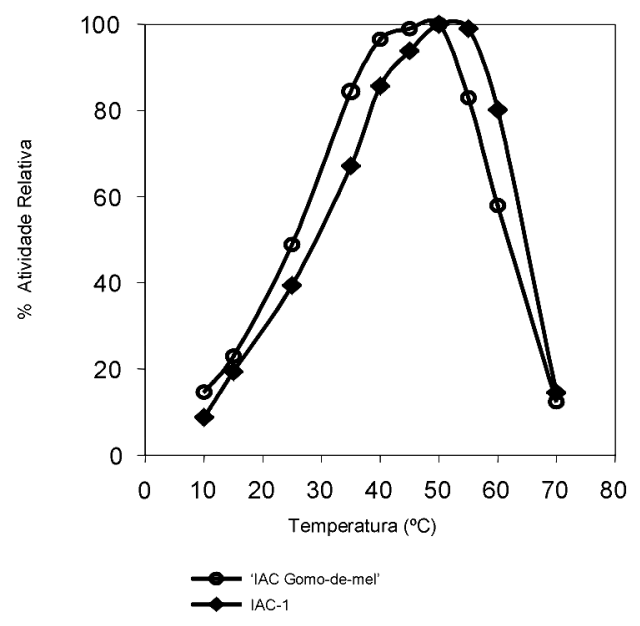

FIGURA 1 - Efeito da temperatura na atividade da peroxidase de extratos brutos dos abacaxis "IAC Gomo-de-mel" e IAC-1

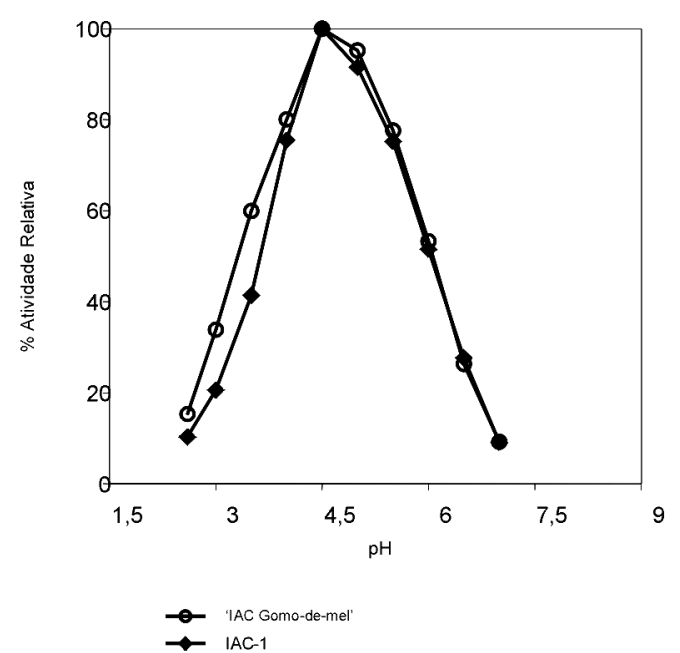

FIGURA 2 - Efeito do $\mathrm{pH}$ na atividade da peroxidase de extratos brutos dos abacaxis "IAC Gomo-de-mel" e IAC-1

$30^{\circ} \mathrm{C}$, e na faixa de $\mathrm{pH} 5,5$ a 7,5 , a $50^{\circ} \mathrm{C}$.

Estas peroxidases mostraram-se estáveis, após 30 minutos, em temperaturas inferiores a $50^{\circ} \mathrm{C}$. Após 30 minutos de tratamento a $70^{\circ} \mathrm{C}$, a atividade residual da peroxidase reduziu-se a 15\% (Figura 3). Após 30 minutos a $80^{\circ} \mathrm{C}$, elas foram inativadas.

Estas peroxidases foram inativadas com tratamentos a 60 e 120 segundos a $90^{\circ} \mathrm{C}$, respectivamente, conforme o mostrado nas Figuras 4 e 5 .

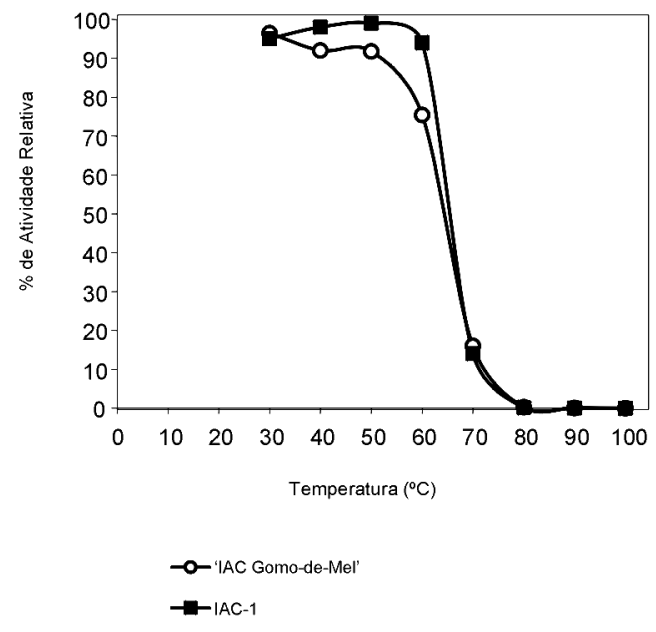

FIGURA 3 - Efeito da temperatura na estabilidade da atividade da peroxidase de extratos brutos dos abacaxis "IAC Gomo-demel" e IAC-1

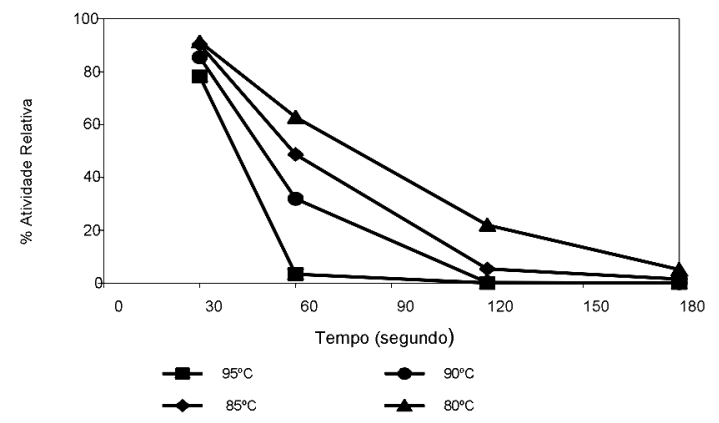

FIGURA 4 - Efeito da temperatura na estabilidade da peroxidase de extrato bruto do abacaxi "IAC Gomo-de-mel

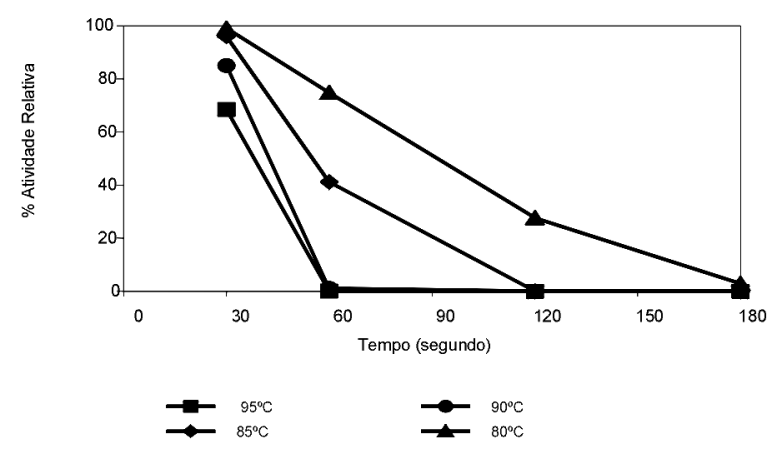

FIGURA 5 - Efeito da temperatura na estabilidade da peroxidase de extrato bruto do abacaxi cultivar IAC-1 
Estes resultados foram semelhantes aos obtido por LIMA [11] que relatou o processamento de suco de abacaxi utilizando-se evaporadores, em que o suco é aquecido a $90^{\circ} \mathrm{C} \mathrm{e} 95^{\circ} \mathrm{C}$, durante 30 e 40 segundos.

MELLO \& CLEMENTE [14] verificaram que a peroxidase solúvel de abacaxi 'Pérola' perdeu cerca de $70 \%$ da atividade, após 420 segundos de tratamento térmico a $60^{\circ} \mathrm{C}$ e cerca de $90 \%$ da atividade, após 600 segundos a $75^{\circ} \mathrm{C}$.

As peroxidases dos abacaxis 'IAC Gomo-de-mel' e IAC-1, da mesma forma que outras peroxidases de frutas, apresentaram estabilidade térmica em temperaturas inferiores a $75^{\circ} \mathrm{C}$, sendo inativada em temperaturas iguais ou superiores a $80^{\circ} \mathrm{C}$.

LOURENÇO E NEVES [12] observaram que a peroxidase de pêssego apresentou rápida inativação acima de $70^{\circ} \mathrm{C}$, com perda praticamente total após tratamento a $80^{\circ} \mathrm{C}$ durante 30 segundos. A peroxidase de melão [10] mostrou-se estável em temperaturas inferiores a $40^{\circ} \mathrm{C}$ e perdeu $90 \%$ da atividade após tratamento a $80^{\circ} \mathrm{C}$ durante 20 minutos.A peroxidase de açaí [18] mostrou-se termoestável,retendo cerca de $70 \%$ da atividade inicial após 10 minutos de tratamento a $70^{\circ} \mathrm{C}$ e cerca de $20 \%$ da atividade após 5 minutos a $90^{\circ} \mathrm{C}$.

A inativação das peroxidases dos extratos brutos dos abacaxis estudados mostraram comportamento não linear, o que também ocorreu em extrato bruto de peroxidase solúvel e peroxidase iônica de abacaxi, submetidos a tratamento a $60^{\circ} \mathrm{C} \mathrm{e} 75^{\circ} \mathrm{C}$ por 10 minutos no máximo[14].

A Tabela 1 indica que o tratamento da peroxidase do abacaxi 'IAC Gomo-de-mel' por 10 minutos a $75^{\circ} \mathrm{C}$ e incubação durante 3 e 24 horas a $5^{\circ} \mathrm{C}$ e $25^{\circ} \mathrm{C}$, houve $10-12 \%$ de regeneração de sua atividade, enquanto que após $2 \mathrm{mi}$ nutos de aquecimento a $90^{\circ} \mathrm{C}$ não se observou regeneração da peroxidase.

TABELA 1 - Regeneração da atividade da peroxidase de extrato bruto do abacaxi "IAC Gomo-de-mel" submetido a tratamento térmico a $75^{\circ} \mathrm{C} \mathrm{e} 90^{\circ} \mathrm{C}$ por diferentes tempos e com diferentes condições de incubação

\begin{tabular}{lc}
\multicolumn{1}{c}{ Tratamento } & $\%$ de Regeneração \\
\hline $75^{\circ} \mathrm{C}$ por 10 minutos e incubação por 3 horas & $10-12 \%$ \\
a $5^{\circ} \mathrm{C}$ ou a $25^{\circ} \mathrm{C}$ & \\
$75^{\circ} \mathrm{C}$ por 10 minutos e incubação por 24 horas & $10-12 \%$ \\
a $5^{\circ} \mathrm{C}$ ou a $25^{\circ} \mathrm{C}$ & \\
$90^{\circ} \mathrm{C}$ por 2 minutos e incubação por 3 horas a & $0 \%$ \\
$5^{\circ} \mathrm{C}$ ou a $25^{\circ} \mathrm{C}$ & \\
$90^{\circ} \mathrm{C}$ por 2 minutos e incubação por 24 horas & $0 \%$ \\
a $5^{\circ} \mathrm{C}$ ou a $25^{\circ} \mathrm{C}$ & \\
\hline
\end{tabular}

A Tabela 2 indica que, após tratamento a $75 \mathrm{C}$ por 10 minutos e incubação durante 3 e 24 horas a $5^{\circ} \mathrm{Ce} 25^{\circ} \mathrm{C}$, a peroxidase do abacaxi IAC- 1 apresenta cerca de $5 \%$ de regeneração, enquanto que após tratamento por 2 minutos a $90^{\circ} \mathrm{C}$, ela não apresenta regeneração.

O resultado obtido foi semelhante ao de MC LELLAN \& ROBINSON [13], que estudaram a regeneração da ati-
TABELA 2 - Regeneração da atividade da peroxidase de extrato bruto do abacaxi IAC-1 submetido a tratamento térmico a $75^{\circ} \mathrm{C}$ e $90^{\circ} \mathrm{C}$ por diferentes tempos e com diferentes condições de incubação

\begin{tabular}{lc}
\hline \multicolumn{1}{c}{ Tratamento } & $\%$ de Regeneração \\
\hline $75^{\circ} \mathrm{C}$ por 10 minutos e incubação por 3 horas a $5^{\circ} \mathrm{C}$ & $5 \%$ \\
ou a $25^{\circ} \mathrm{C}$ & \\
$75^{\circ} \mathrm{C}$ por 10 minutos e incubação por 24 horas a $5^{\circ} \mathrm{C}$ & $5 \%$ \\
ou a $25^{\circ} \mathrm{C}$ & \\
$90^{\circ} \mathrm{C}$ por 2 minutos e incubação por 3 horas a $5^{\circ} \mathrm{C}$ ou & $0 \%$ \\
a $25^{\circ} \mathrm{C}$ & \\
$90^{\circ} \mathrm{C}$ por 2 minutos e incubação por 24 horas a $5^{\circ} \mathrm{C}$ & $0 \%$ \\
ou a $25^{\circ} \mathrm{C}$ & \\
\hline
\end{tabular}

vidade de peroxidase de laranja após tratamento a $60^{\circ} \mathrm{C}$, $65^{\circ} \mathrm{C}, 70^{\circ} \mathrm{C}$ e $75^{\circ} \mathrm{C}$ por 10 minutos que também foram baixas, enquanto que SANTOS [18] estudando a peroxidase de açaí observou regeneração de $30 \%$ e de $5 \%$, após 5 minutos de tratamento a $80^{\circ} \mathrm{C} \mathrm{e} 90^{\circ} \mathrm{C}$, respectivamente.

As Figuras 6 e 7 indicam que as peroxidases dos abacaxis IAC-1 e 'IAC Gomo-de-mel' se mostraram estáveis na faixa de pH 4,0 a 9,0, após 24 horas de incubação a

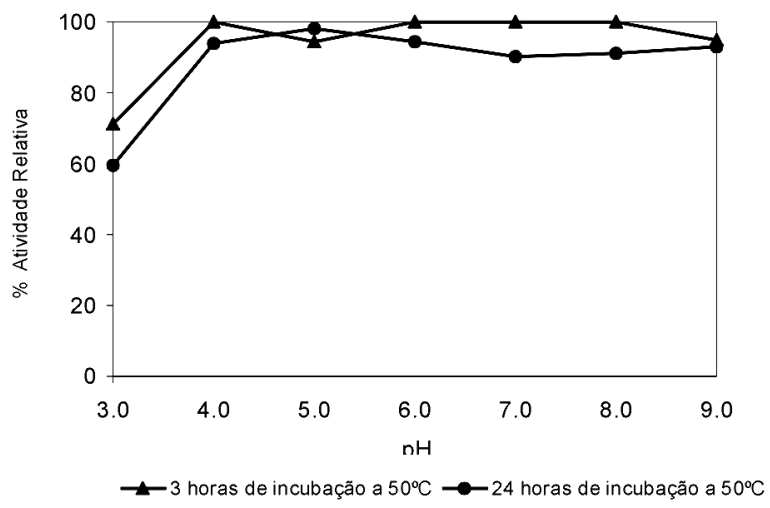

FIGURA 6 - Efeito do $\mathrm{pH}$ na estabilidade da peroxidase de extrato bruto do abacaxi "IAC Gomo-de-mel

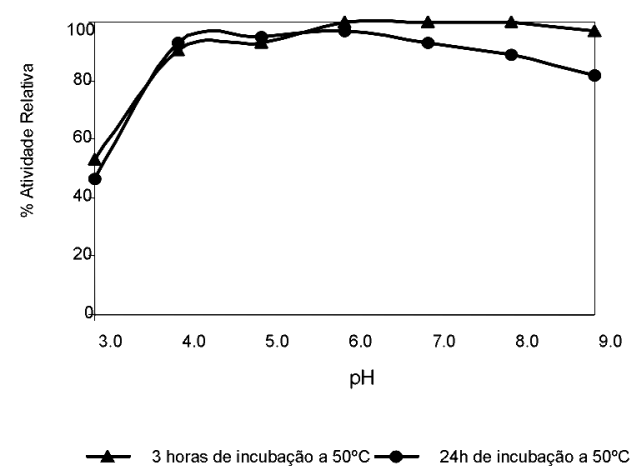

FIGURA 7 - Efeito do $\mathrm{pH}$ na estabilidade da peroxidase de extrato bruto do abacaxi IAC-1 
$50^{\circ} \mathrm{C}$, retendo mais de $80 \%$ de atividade, sendo que em $\mathrm{pH} 3,0$ a peroxidase do IAC- 1 reteve cerca de $45 \%$ da atividade inicial e 'IAC Gomo-de-mel' 60\%.

As peroxidades dos abacaxis estudados da mesma forma que as peroxidases de outras frutas, apresentaram estabilidade em ampla faixa de $\mathrm{pH}$. A peroxidase de carambola apresentou estabilidade na faixa de $\mathrm{pH} 6,0$ a 9,0 [8], enquanto que a do morango em $\mathrm{pH} 4,0$ a 11,0 , sendo que entre 6,0 e 7,5 manteve $90 \%$ da atividade inicial [3]. A peroxidase de açaí [18] apresentou estabilidade em ampla faixa de $\mathrm{pH}$, mantendo mais que $50 \%$ da atividade inicial após 24 horas de incubação a $5^{\circ} \mathrm{C}$ na faixa de pH 2,6 a 10,0.

\section{4 - CONCLUSÕES}

As peroxidases dos abacaxis "IAC Gomo-de-mel" e IAC- 1 apresentaram atividade ótima a $45-50^{\circ} \mathrm{C}$ e $50-$ $55^{\circ} \mathrm{C}$, respectivamente. Essas peroxidases apresentaram atividade ótima em $\mathrm{pH}$ 4,5 e mostraram-se estáveis na faixa de pH 4,0 - 9,0, após 24 horas de incubação a $50^{\circ} \mathrm{C}$, retendo mais que $80 \%$ de atividade inicial. Foi observada regenaração das peroxidases dos abacaxis da ordem de $5 \%$ no IAC-1 e de $10-12 \%$ no 'IAC Gomo-de-mel', após aquecimento a $75^{\circ} \mathrm{C}$ por 10 minutos, seguido de incubação a $5^{\circ} \mathrm{C}$ ou a $25^{\circ} \mathrm{C}$. As peroxidases destes abacaxis foram inativadas após 2 minutos a $90^{\circ} \mathrm{C}$, não sendo observado regeneração.

\section{5 - REFERÊNCIAS BIBLIOGRÁFICAS}

[1] BRAVERMAN, J.B.S. Vitaminas. In:__ Introduction a la bioquímica de los alimentos. Barcelona: Omega, 1967, cap. 14, p. 206-239.

[2] BeAUdREAU,C, YASUNOBU, K.T. Heme Proteins.VI Crystaline pineapple peroxidase B . Biochemistry. Washington DC., v.5, n.4., p.1404-1412, 1966.

[3] Civello,P.M; MARTineZ,G.A.; ChaVes,A.R.; AÑON,M.C. Peroxidase from strawberry fruit (Fragaria ananassa Duch) : Partial purification and determination of some properties. Journal of Agricultural and Food Chemistry, Washington DC, v.43, p.2596-2601, 1995

[4] FERREIRA, F. R.; CABRAL, J.R.S. Melhoramento genético. Abacaxi: tecnologia de produção e comercialização. Informe Agropecuário, Belo Horizonte, 1998, v. 19,n.195, p.24-28.

[5] HAARD, N.F. Physiologycal roles of peroxidase in postharvest fruits and vegetables. In: ORY, R.L; S.t ANGELO, A.T., Ed. Enzymes in food and beverages process, ACS Symposium Series, 1977. cap.9, p. 143171.

[6] HAMMER, F.E. Oxidoredutases. In: NAGODAWITHANA, T., REED, G (Ed) Enzymes in food processing, England: Academic Press, 1993, p.233-243.

[7] HEMEDA, H.M.; KLEIN, B. P. Effects of naturally occuring antioxidants on peroxidase activity of vegetables extracts. Journal of Food Science, New York, v. 55 , p. $184-185,1990$.
[8] HOLSCHUCH, H.J. Isolamento, purificação e caracterização bioquímica da peroxidase de carambola (Averrhoa carambola,L.) 2000. 159 p. Tese (Doutorado em Ciência de Alimentos). Faculdade de Engenharia de Alimentos, Universidade Estadual de Campinas.

[9] KHAN, A. A.; ROBINSON, D.S. Hydrogen donor specifity of mango isoperoxidases. Food Chemistry, Londres, v. 49, n. 4, p. 407-410, 1994.

[10] LAMIKANRA, O; WATSON,M.A. Cantaloupe melon peroxidase: Characterization and effects of additives on activity. Nahrung-Food, Berlim, v.44, n.3, p.168-172, 2000.

[11] LIMA, U. A. Agroindustrialização de frutas. Piracicaba: Fundação de Estudos Agrários "Luiz de Queiroz", 1998, v. 5 , p. 151 .

[12] LOURENÇO, E.J.; NEVES, V.A., Peroxidase solúvel de pêssego: Purificação parcial e propriedades. Ciênc. Tecnol. Aliment., Campinas, v. 17, n.1. p.42-48, 1997.

[13] MC LELLAN K. M.; ROBINSON, D.S. Heat stability of peroxidases from orange. Food Chemistry, Londres, v. 13 , p. 139-147, 1984.

[14] MELLO, E.T.; CLEMENTE, E. Thermostability of crude extract of peroxidase from pineapple. Revista Unimar, Marília, v. 18, n. 4, p. 757-763, 1996.

[15] MOULDING ,P.H., GRANT,H.F., McLELlAN,K.M., ROBINSON,D.S., Heat stability of soluble and ionically bound peroxidases extracted from apples. International Journal of Food Science and Technology, London, V.22, p.291-397,1987

[16] RICHARDSON, T., HYSLOP,D.B. Enzymes. In: FENNEMA, O. R. Food chemistry, 2 ed. ,New York: Marcel Dekker, Inc. 1985, p. 451-452.

[17] ROBINSON, D.S. Peroxidases and their significance in fruits and vegetables. In: FOX, P.F. (Ed), Food enzymology. London and New York: Editora, p. 399426, 1991.

[18] SANTOS, E.R. Caracterização bioquímica da peroxidase e da polifenoloxidase de açai (Euterpe oleraceae). 2002. 104p. Tese (Mestrado em Ciência de Alimentos). Faculdade de Engenharia de Alimentos, Universidade Estadual de Campinas.

[19] SODA, I., HASEGAWA,T., SUZUKI,T., OGURA,N., Purification and some properties of peroxidase from kiwifruit. Agricultural and Biological Chemistry, Tokyo, v.55, n.6, p.1677-1678, 1991.

[20] USBERTI FILHO, J. A.; SIQUEIRA, W. J.; SPIRONELLO, A.; TANAKA, M.A.S.; SIGRIST, J.M.M.; MARTINS, A.L.M.; BORTOLETTO, N.; TSUHAKO AT.; GUSHIKEN, A. IAC Gomo-de-mel. Campinas: Instituto Agronômico de Campinas, 1999. (Folder)

[22] VÁMOS-VIGYÁZÓ, L. Polyphenoloxidase and peroxidase in fruits and vegetable. CRC Criticals Reviews in Food Science and Nutrition, Cleveland, 1981 , v.15, p. 49127.

[22] WHITAKER,J.R. Catalase and Peroxidase. Principles of enzymology for the food science, 2 ed., New York ,Marcel Dekker-Inc., 1994, p. 565-577. 


\section{5 - AGRADECIMENTOS}

À FAPESP - Fundação de Amparo à Pesquisa do Estado de São Paulo, pela concessão de auxilio financeiro. Processo número: 99/11092-4. 